\title{
Extracorporeal Membrane Oxygenation for Cardiotoxic Drug Overdose-A Lifesaving Intervention
}

\author{
Sundar Singh Subash ${ }^{1}$ Nandakumar Madhusoodhanan Nandanam ${ }^{1}$ Placid Siroraj Alphonse ${ }^{1}$ \\ Vijay Thomas Cherian² Shaji Palangadan² Suresh Kumar ${ }^{3}$
}

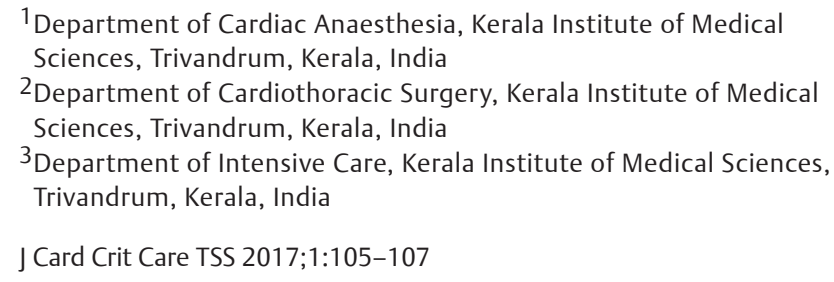

Address for correspondence Sundar Singh Subash, MD, DM, FTEE, FIAE, Department of Cardiac Anaesthesia, Kerala Institute of Medical Sciences, PB No: 1, Anayara, Trivandrum, Kerala, India 695029 (e-mail: sssubash@yahoo.com).
Abstract
Keywords
- calcium channel blocker poisoning
- angiotensin receptor antagonist poisoning
- extracorporeal memb- rane oxygenation
- refractive shock

Extracorporeal membrane oxygenation (ECMO) use in cardiotoxic drug overdose is increasing. Calcium channel blockers along with $\beta$-blockers constitute more than $65 \%$ of deaths from cardiovascular medications. The authors report here a case of ECMO use for amlodipine and telmisartan tablet overdose, where ECMO was used to salvage the patient's life as a life-saving intervention.

\section{Introduction}

Calcium channel blocker (CCB) constitutes $34 \%$ of cardiovascular drug-related deaths. ${ }^{1}$ When multiple cardiovascular drugs with synergistic mechanisms are ingested together, the management of such patients becomes more challenging and refractive to most medical management. Extracorporeal membrane oxygenation (ECMO) can become a lifesaving intervention in such a situation, when not responding to other medical management.

\section{Case Report}

A 28-year-old female patient was brought to the hospital with alleged history of consumption of amlodipine $300 \mathrm{mg}$ and telmisartan $120 \mathrm{mg}$, in a suicide attempt. She was brought to the hospital after 5 hours of ingestion of these tablets. At the time of admission, she was conscious, oriented, and responding to verbal commands. Her vitals were as follows: heart rate 110 beats/min, blood pressure (BP) 80/50 mm Hg, and $\mathrm{Spo}_{2} 98 \%$ at room air. Her cardiovascular and respiratory examinations were normal.
The patient was initially managed with activated charcoal via nasogastric tube, normal saline infusion bolus, Inj. noradrenaline started at $0.1 \mu \mathrm{g} / \mathrm{kg} / \mathrm{min}$, and Inj. calcium gluconate. She was shifted to intensive care unit, and her BP continued to decrease. Inj. noradrenaline increased to $0.5 \mu \mathrm{g} / \mathrm{kg} / \mathrm{min}$, and Inj. adrenaline $0.5 \mu \mathrm{g} / \mathrm{kg} / \mathrm{min}$, Inj. vasopressin $4.8 \mathrm{U} / \mathrm{h}$, and Inj. phenylephrine $14 \mu \mathrm{g} / \mathrm{kg} / \mathrm{min}$ were also added. Inj. glucagon infusion at $4 \mathrm{mg} / \mathrm{h}, 20 \%$ smof lipid $100 \mathrm{~mL}$, and calcium gluconate $10 \%$ infusion at 10 $\mathrm{mL} / \mathrm{h}$ were also initiated. Considering the amlodipine poisoning, hyperinsulinemic-euglycemic mixture was also tried. In spite of these aggressive medical managements, her BP never showed any improvement. The patient was intubated considering her hemodynamic disturbances. Her arterial blood gas (ABG) showed severe metabolic acidosis with $\mathrm{PH} 7.10$, and she went into severe vasoplegic state with acute renal failure. Transthoracic echocardiography showed good left ventricular function, normal functioning valves, and ejection fraction $60 \%$. Considering her failure to show any improvement for aggressive medical management, the decision was made to support the patient with VA ECMO.
DoI https://doi.org/ $10.1055 / \mathrm{s}-0038-1626678$ ISSN 2457-0206.
Copyright $\odot 2017$ Official Publication of The Simulation Society (TSS), accredited by International Society of Cardiovascular Ultrasound (ISCU)
License terms

() (1) $\Theta \circledast$ 
The VA ECMO circuit consisted of Rotaflow centrifugal pump, Quadrox oxygenator, 22F venous cannula in the right femoral vein, $17 \mathrm{~F}$ arterial cannula in the left femoral artery, and $10 \mathrm{~F}$ arterial cannula in the same artery for distal perfusion. The cannulas were placed under transesophageal echocardiographic guidance (-Figs. 1-4). The flow was maintained at $4.2 \mathrm{~L} / \mathrm{min}$ and sweep gas flow rate of $3 \mathrm{~L} / \mathrm{min}$ with $\mathrm{Fio}_{2} 100 \%$. Activated clotting time was maintained between 180 and 200 seconds with heparin infusion, and the patient was ventilated with synchronous intermittent

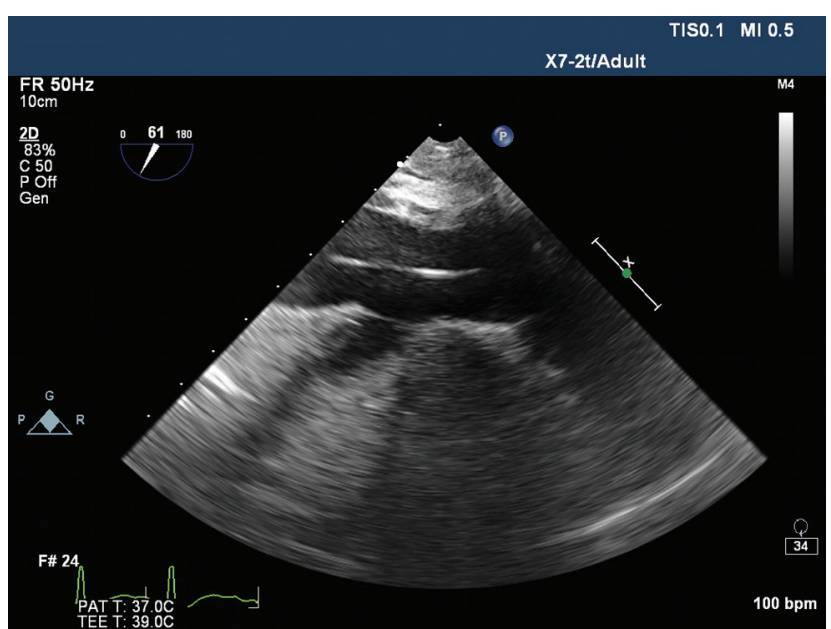

Fig. 1 Hepatic vein view showing guide wire in inferior vena cava.

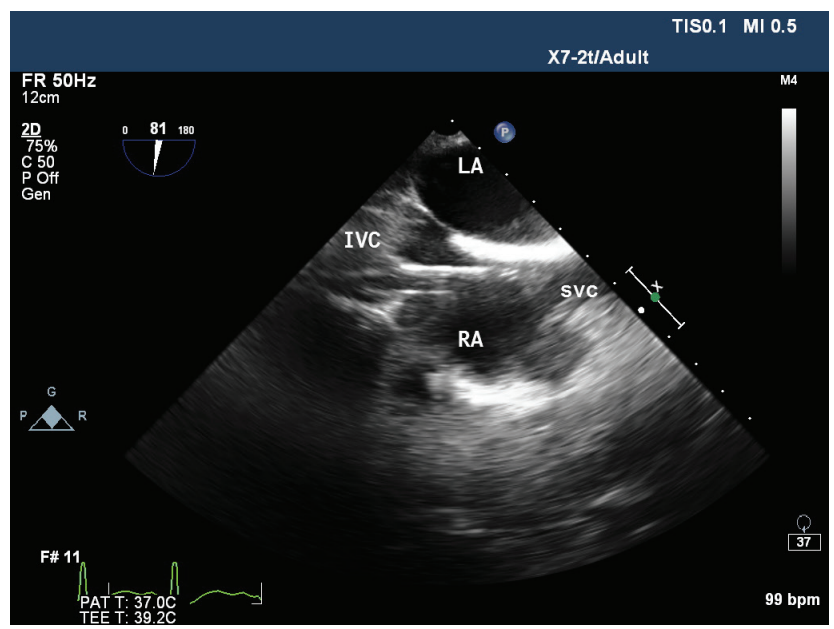

Fig. 3 Mid oesophageal Bicaval view showing venous cannula in right atrium. IVC, inferior vena cava; LA, left atrium; RA, right atrium; SVC, superior vena cava. mandatory ventilation (SIMV) mode with tidal volume 200 $\mathrm{mL}$, respiratory rate 10 breaths/min, positive end-expiratory pressure $7 \mathrm{~mm} \mathrm{Hg}$, and $\mathrm{Fio}_{2} 35 \%$. She was supported with VA ECMO for 5 days, and vasopressors and inotropes were gradually weaned with ongoing VA ECMO support. Her laboratory values were shown in - Table 1. On fifth day, she was successfully weaned from VA ECMO and decannulated. The following day, she was weaned from ventilator and extubated. She was discharged on 12th day, and follow-up after 2 months showed favorable outcome.

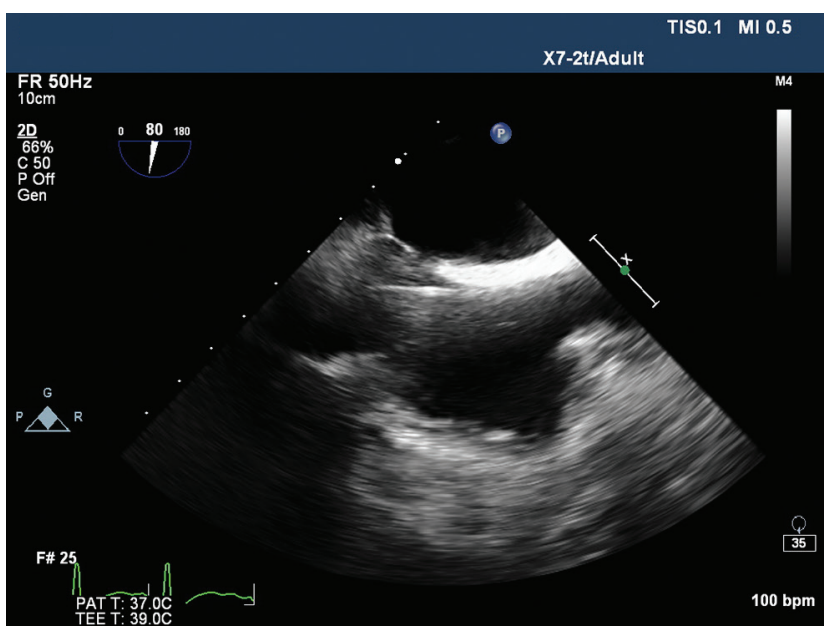

Fig. 2 Mid oesophageal bicaval view showing guide wire in right atrium.

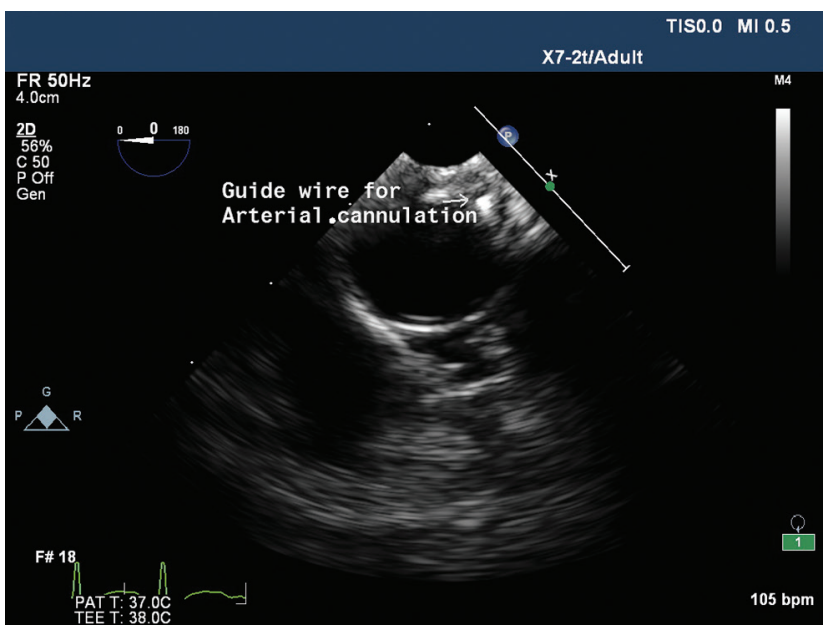

Fig. 4 Descending thoracic aorta short axis view showing guide wire.

Table 1 Laboratory values on ECMO

\begin{tabular}{|l|l|l|l|l|l|l|l|}
\hline Days & $\mathrm{Hb}(\mathrm{g} / \mathrm{dL})$ & $\mathrm{TLc}($ cells/mm $)$ & $\begin{array}{l}\text { Platelets } \\
\text { (thous/mm })\end{array}$ & $\mathrm{Na}^{+}(\mathrm{mEq} / \mathrm{L})$ & $\mathrm{K}^{+}(\mathrm{mEq} / \mathrm{L})$ & Urea $(\mathrm{mg} / \mathrm{dL})$ & $\begin{array}{l}\mathrm{Creatinine} \\
(\mathrm{mg} / \mathrm{dL})\end{array}$ \\
\hline 1 & 13.2 & 39,600 & 342 & 149 & 3.8 & 7.7 & 1.6 \\
\hline 2 & 14.5 & 40,000 & 207 & 149 & 2.5 & 9.0 & 0.8 \\
\hline 3 & 13.2 & 48,100 & 128 & 143 & 5.1 & 7.0 & 0.8 \\
\hline 4 & 12.0 & 42,500 & 88 & 138 & 5.7 & 14.4 & 1.4 \\
\hline 5 & 10.9 & 19,000 & 64 & 143 & 4.0 & 18.6 & 1.4 \\
\hline 6 & 12 & 10,900 & 79 & 145 & 4.0 & 17.9 & 1.4 \\
\hline
\end{tabular}




\section{Discussion}

CCB and angiotensin receptor blocker overdose can cause serious mortality and morbidity. Half-life of amlodipine and telmisartan are 34 to 50 hours and 24 hours, respectively. ${ }^{2}$ The overdose of these drugs can cause profound refractory hypotension, bradyarrhythmias, and shock. The combination of these drugs may blunt the sympathetic and vasoconstrictive responses and worsen CCB toxicity. ${ }^{3}$ These drugs are not dialyzable because they are highly protein bound with large volume of distribution. ${ }^{4}$

The medical management of CCB drug overdose includes general and specific measures. General measures include stomach wash via nasogastric tube with activated charcoal. Special measures include administration of vasoconstrictors, intravenous calcium gluconate, and Inj. glucagon that acts by increasing intracellular cyclic adenosine monophosphate (cAMP). Hyperinsulinemia-euglycemia therapy involves infusion of high dose of insulin along with $25 \%$ dextrose to maintain euglycemia. Insulin has positive inotropic action, increases plasma levels of ionized calcium, and improves the myocardial use of carbohydrates instead of free fatty acids. ${ }^{5}$ Lipid emulsion forms an expanded lipid phase in blood and helps in redistribution and trapping of tissue bound drug. ${ }^{6}$ Methylene blue helps in scavenging the nitric oxide. ${ }^{7}$ In this patient, all these drugs were used except methylene blue because of nonavailability of the drug, and these medical managements did not show any improvement.

Toxicology consultation has shown that ECMO is still rarely used in poisoned patients; 10 out of 26,271 patients were reported over a 3-year period. ${ }^{8}$ Because this patient did not show any improvement to medical management along with refractory shock and acute renal failure, the authors decided to go ahead with VA ECMO. The goal of the VA ECMO was to temporarily support the hemodynamics and respiration until the drug got metabolized from her body. Even though ECMO has disadvantages such as not readily available and high cost, it can be a lifesaving intervention when medical management fails.

\section{Conclusion}

When medical therapy is ineffective for cardiotoxic drug overdose, ECMO may be a lifesaving intervention.

\section{References}

1 Bronstein AC, Spyker DA, Cantilena LR Jr, Rumack BH, Dart RC. 2011 Annual report of the American Association of Poison Control Centers' National Poison Data System (NPDS): 29th Annual Report. Clin Toxicol (Phila) 2012;50(10):911-1164

2 Abernethy DR. The pharmacokinetic profile of amlodipine. Am Heart J 1989;118:1100-1103

3 Smith SW, Ferguson KL, Hoffman RS, Nelson LS, Greller HA. Prolonged severe hypotension following combined amlodipine and valsartan ingestion. Clin Toxicol (Phila) 2008;46(5): 470-474

4 Dewitt CR, Waksman JC. Pharmacology, pathophysiology and management of calcium channel blocker and beta-blocker toxicity. Toxic Rev 2004;23:223-238

5 Yuan TH, Kerns WP II, Tomaszewski CA, Ford MD, Kline JA. Insulin-glucose as adjunctive therapy for severe calcium channel antagonist poisoning. J Toxicol Clin Toxicol 1999;37(4): 463-474

6 Turner-Lawrence DE, Kerns Ii W. Intravenous fat emulsion: a potential novel antidote. J Med Toxicol 2008;4(2):109-114

7 Shanmugam G. Vasoplegic syndrome-the role of methylene blue. Eur J Cardiothorac Surg 2005;28(5):705-710

8 Maskell KF, Ferguson NM, Bain J, Wills BK. Survival after cardiac arrest: ECMO rescue therapy after amlodipine and metoprolol overdose. Cardiovasc Toxicol 2017;17(2):223:225 